удК 658

Н. Н. Грибанова

Байкальский государственный университет, г. Иркутск, Российская Федераџия

А. Ф. Шуплецов

Байкальский государственный университет, 2. Иркутск, Российская Федерация

\title{
ОСОБЕННОСТИ ПЛАНИРОВАНИЯ И ПРОГНОЗИРОВАНИЯ КОМПАНИЙ НА ОСНОВЕ ИНФОРМАЦИОННЫХ МОДЕЛЕЙ
}

\begin{abstract}
АНнотАция. На сегодняшний день, для руководителей компаний, главной особенностью для принятия своевременных управленческих решений становится информационное обеспечение, заключающееся в сборе и переработке информации. Информация необходима для подготовки соответствующих докладов, отчетов, предложений для выработки и принятия стратегических и тактических решений по управлению компанией.

Чтобы повысить эффективность применения информации, необходимо построить и совместить информационные системы, что в свою очередь позволит устранить дублирование и предоставит условия для многократного использования информации, а также необходимо определить интеграционные связи, сократить объем информационных потоков, увеличить уровень использования информации. На современном этапе актуальным становится поиск стратегических решений того, как, обладая в избытке информацией, повысить свою способность чутко и быстро реагировать на изменение условий рынка. Стратегический путь в этом направлении - автоматизация моделирования экономических процессов.

кЛючЕВЫЕ словА. Планирование; прогнозирование; информационные модели; моделирование; стратегия.

ИНФОРМАЦИЯ О СТАТЬЕ. Дата поступления 9 июня 2017 г.; дата принятия к печати 11 октября 2017 г.; дата онлайн-размещения 25 октября 2017 г.
\end{abstract}

N. N. Gribanova

Baikal State University, Irkutsk, Russian Federation

A. F. Shupletsov Baikal State University, Irkutsk, Russian Federation

\section{FEATURES OF CORPORATE PLANNING AND FORECASTING ON THE BASIS OF INFORMATION MODELS}

\begin{abstract}
So far, the main feature for corporate management in making well-timed managerial decisions is the information support involving collection and processing information. Information is necessary for preparing respective statements, reports, proposals for working out and making strategic and tactical decisions on corporate management. In order to increase the use of information, it is necessary to build up and combine information systems, which in its turn will allow to eliminate the doubling and provide the conditions of multiple use of information, and also it is necessary to determine the integrational ties, to reduce the amount of information flows, to increase the level of information use.
\end{abstract}

KEYWORDS. Planning; forecasting; information models; modeling; strategy.

ARTICLE INFO. Received June 9, 2017; accepted October 11, 2017; available online October 25, 2017.

\section{Baikal Research Journal}


Экономико-математические и информационные модели реализуются в виде компьютерных программ и являются составной частью «банка знаний» компании и ее информационной системы. Необходимо принять во внимание формирование учетно-аналитических информационных потоков в компьютерной среде, которые обеспечивают горизонтальные и вертикальные связи системы, не нарушая основные принципы рационального управления, необходимые для эффективного функционирования компании. Важно предоставить компании текущую и оперативную картину, дать возможность ориентироваться, когда и из каких источников планируется поступление денежных средств, на какие цели будет происходить расходование денег и какие будут финансовые показатели к концу отчетного периода [1, c. 145].

Особенности прохождение этапов в построении модели прогнозирования деятельности компании:

- анализ финансовых, организационных, кадровых и других материальных показателей. Основное внимание будет уделяться основным показателям - объем реализации, затраты, прибыль. Предполагаемые действия позволят оценить финансовое состояние деятельности компании и установить проблемы компании;

- разработка алгоритма стратегии по ключевым направлениям финансовой деятельности компании. Данный этап - это составление прогнозных документов;

- конкретизация показателей прогнозных документов - формирование финансовых планов;

- на четвертом этапе произойдет соединение показателей финансовых планов с производственными, коммерческими, инвестиционными, строительными и другими планами и программами, разрабатываемыми предприятием.

- пятый этап - это построение финансового прогноза компании с применением персональных компьютеров, завязанных в сеть и созданием тестовой программы для расчета прогнозных оценок [2, с. 75].

Экономический анализ финансовой деятельности не регламентирован, отсутствуют стандартные отечественные методики его постановки и функционирования в компании. Существующие западные методики требуют адаптации из-за различий в условиях ведения бизнеса, а разрабатываемые отечественные носят, как правило, заказной характер и ориентированы на конкретные компании. В связи с этим разработка теоретических основ планирования и прогнозирования носит многогранный и субъективный характер, имеющий узкоспециализированный характер. Прогнозные оценки деятельности предприятия - это комплекс мер по составлению системы функционирования и развития предприятия в натуральном и стоимостном выражении для обеспечения бесперебойной успешной работы на перспективу [3, с. 89].

В современных условиях, именно малые и средние компании должны быстро реагировать на изменения спроса на рынке и оперативно его удовлетворять. Успешные из них строят работу на этом принципе экономики. Подспорьем в этом вопросе является план-график, а для его динамичного изменения - автоматизированная программа прогнозных оценок. Но автоматизированная программа прогнозных оценок - это в идеале и, возможно, на крупных субъектах, имеющих зарубежные программы. Компании среднего звена и более мелкие могут только мечтать об автоматизации расчета прогнозных оценок из-за их сложности и цены [4].

Для принятия решения, связанных с планированием и прогнозированием деятельности компании, руководство зачастую применяет метод экспертных оценок, предусматривающие анкетирование экспертами по специальным схемам и анализ полученных результатов при использовании инструментов экономической статистики и стохастических методов, которые подразумевают вероятностный характер

\section{Baikal Research Journal}

электронный научный журнал Байкальского государственного университета 
прогноза и связи между исследуемыми показателями. Метод Делфи заключается в проведении анкетирования специалистов определенной области знаний. Данные, полученные при анкетировании, подлежат статистической обработке, формирующие диапазон мнений экспертов, в котором отражаются коллективное мнение экспертов по определенной проблеме. Самым же значительным фактором, влияющим на точность прогнозирования, является руководитель компании [5, с. 26-75].

Расчет прогнозных оценок часто осуществляют на основе анализа товарообмена. Основной задачей построения системы прогнозных оценок является проблема контроля за изменением цен на отдельные виды товаров, присутствующих на рынке. Этот метод является укрупненным.

План-график использует ряд исходных данных таких как: финансовые планы, потребительский спрос, производственную мощность, возможности трудовых ресурсов, колебания запасов, оценки поставщиков и другие данные. Сводит все эти данные к единому показателю плановый отдел и в течение довольно продолжительного промежутка времени. Это зачастую снижает ценность выходной информации.

Исследование пооперационного анализа технологического процесса проводится с целью автоматизации учета временных затрат на каждой операции и превращение их в денежную оценку в конце производственного процесса. Итоговая задача расчетов - составление программы для расчета прогнозных оценок работы компании с минимальными временными затратами на проведение оценки работы на перспективу. Сравнение прогнозных оценок с фактическими по прошествии прогнозного периода позволит с высокой точностью определить потери на рабочем месте и выявить узкие места.

Чтобы создать автоматизированную систему прогнозирования деятельности компании необходимо нормировать трудовые ресурсы, запасы, электро- и теплоэнергии, нормирование производственных и непроизводственных расходов, т.е. всей системы деятельности компании. В связи с этим внедрение данных систем автоматизации прогнозирования зачастую необходимо отказаться от существующей системы управления, в следствии чего изменится движение всей информации, менталитета работников предприятия на всех структурных уровнях управления [6].

Во многих компаниях среднего звена на сегодняшний день существующая система внутрифирменного прогнозирования не предполагает многовариантный анализ финансовых последствий реализации намеченных планов, не предусматривает анализ различных сценариев изменения финансового состояния фирмы. Учитывая это, можно подчеркнуть, что жестко предопределенных и однозначных решений нет.

Следует отметить, что роль и предназначение прогнозирования как функции управления деятельностью экономической системы не в точном расчете тех или иных показателей, а в определении направления стратегии в быстро меняющихся внешних условиях хозяйствования. Эта работа призвана находить внутренние резервы, соблюдать режим экономии. Получение прогнозного размера прибыли и других финансовых показателей возможно лишь при условии соблюдения норм затрат труда и материальных ресурсов. Следствием этих расчетов является устранение чрезмерных запасов материальных ресурсов, сокращение непроизводительных расходов, внеплановых финансовых инвестиций. [7]. Благодаря расчету прогноза деятельности создаются условия для эффективного использования производственных мощностей, повышения качества продукции [8, с. 78].

Разработка программы автоматизации расчетов прогнозных оценок не ставит своей целью дать рекомендации по изменению технологического процесса, хотя и может оказать влияние на выявление узких мест производственного процесса.

\section{Baikal Research Journal}

электронный научный журнал Байкальского государственного университета 
Составление алгоритма прогнозных оценок деятельности является как бы надстроечным инструментом, позволяющим руководителю без привлечения дополнительных работников бухгалтерии оперативно оценивать стратегические варианты в работе предприятия [9, с. 84].

Работа технологов и экономистов с целью организации технологического процесса и управление им, как это имеет место на основной части мелких и средних субъектов экономики, не приносит должных результатов. Анализ коэффициентов баланса не может оказывать какого-либо влияния на организацию технологического процесса.

С другой стороны технолог руководствуется лишь совершенствованием технологического процесса с отдаленной ориентацией на экономические и технические коэффициенты эффективности работы, как своего участка работы, так и бизнеса в целом. Экономист считает затраты, директор принимает решения на основе собранной информации с производственных отделов.

Для осуществления автоматизации прогнозных оценок необходимо на предприятии иметь или разработать комплект технологической и конструкторской документации, которая касается организации технологического процесса производства [10].

Технологические процессы разрабатываются технологом в виде плана-графика, в котором устанавливаются этапы освоения изделия, перечень работ по технологической подготовке производства и продолжительность их выполнения, состав подразделений-исполнителей и ответственные исполнители по каждому подразделению.

В заключении отметим, что результатом исследования операций явится отказ от традиционных методов планирования, существующей практики деления планирования на технико-экономическое и оперативное. Конечным результатом системы автоматизации планирования средств компании станет представление движения финансовой информации в максимально удобной форме для руководителя. Это позволит представить соответствующие показатели хозяйственной деятельности для принятия эффективных управленческих решений.

\section{Список использованной литературы}

1. Балдин К. В. Информационные системы в экономике : учебник / К. В. Балдин. 4-е изд., перераб. и доп. - М. : Дашков и К, 2007. - 210 с.

2. Водянова Ю. И. ЕRP системы. Современное планирование и управление ресурсами предприятия. Выбор, внедрение, эксплуатация / Ю. И. Водянова. - М. : Вершина, 2004. $236 \mathrm{c}$.

3. Годин В. В. Управление информационными ресурсами: 17-модульная программа для менеджеров «Управление развитием организации» / В. В. Годин, И. К. Корнеев. - М. : ИНФРА-М, $2000-346$ с.

4. Грушина О. В. Внутрифирменное планирование в контексте системно - информационного анализа процессов управления / О. В. Грушина // Проблемы теории и практики управления. -2009 . - № 3. - С. $80-84$.

5. Савиных В. Н. Математическое моделирование производственного и финансового менеджмента : учеб. пособие / В. Н. Савиных.— М. : Кнорус, 2014. - 192 с.

6. Беляев В. К. Планирование на предприятии : учеб. пособие / В. К. Беляев. - Иркутск : Изд-во БГУЭП, 2011. - 100 с.

7. Самаруха А. В. Прогнозирование регионального развития при переходе России на инновационную модель экономики : учеб. пособие / А. В. Самаруха. - Иркутск : Изд-во БГУЭП, 2013. - 240 с.

8. Вологнина О. А. Математическое моделирование экономических процессов и систем : учеб. пособие / О. А. Волгнина. - М. : КНОРУС, 2012. - 196 с.

\section{Baikal Research Journal}


9. Кокаева Т. Т. О некоторых аспектах использования информационных технологий в управлении малыми предприятиями / Т. Т. Кокаева, А. Е. Бердникова, Т. Т. Бугулова // Известия Горского гос. аграрного ун-та. - 2013. - Т. 50, № 1. - С. 285-289.

10. Морошкин В. А. Бизнес-планирование : учеб. пособие / В. А. Морошкин, В. П. Буров. - М. : Форум, 2011. - 287 с.

\section{References}

1. Baldin K. V. Informatsionnye sistemy $v$ ekonomike [Information systems in economy]. Moscow, Dashkov i K Publ., 2007. 210 p.

2. Vodyanova Yu. I. ERP sistemy. Sovremennoe planirovanie $i$ upravlenie resursami predpriyatiya. Vybor, vnedrenie, ekspluatatsiya [ERP systems: present-day planning and corporate resource management. Selection, introduction, maintenance]. Moscow, Vershina Publ., 2004. 236 p.

3. Godin V. V., Korneev I. K. Upravlenie informatsionnymi resursami: 17-modul'naya programma dlya menedzherov «Upravlenie razvitiem organizatsii» [Information resource management: 17-module program for managers «Management of corporate development»]. Moscow, INFRA-M Publ., 2000. 346 p.

4. Grushina O. V. Intracorparate planning in context of system-information analysis of management processes. Problemy teorii $i$ praktiki upravleniya = Problems of Theory and Practice of Management, 2009, no. 3, pp. 80-84. (In Russian).

5. Savinykh V. N. Matematicheskoe modelirovanie proizvodstvennogo $i$ finansovogo menedzhmenta [Mathematical modelling of industrial and financial management]. Moscow, Knorus Publ., 2014. 192 p.

6. Belyaev V. K. Planirovanie na predpriyatii [Planning at the company]. Irkutsk, Baikal State University of Economics and Law Publ., 2011. 100 p.

7. Samarukha A. V. Prognozirovanie regional'nogo razvitiya pri perekhode Rossii na innovatsionnuyu model' ekonomiki [Forecasting of regional development in Russia's transition to innovative model of economy]. Irkutsk, Baikal State University of Economics and Law Publ., 2013. 240 p.

8. Volognina O. A. Matematicheskoe modelirovanie ekonomicheskikh protsessov i sistem [Mathematical modelling of economic processes and systems]. Moscow, Knorus Publ., 2012. $196 \mathrm{p}$.

9. Kokaeva T. T., Berdnikova A. E., Bugulova T. T. On some aspects of using information technologies in managing small businesses. Izvestiya Gorskogo gosudarstvennogo agrarnogo universiteta $=$ Journal of Proceedings of the Gorsky SAU, 2013, vol. 50, no. 1, pp. 285-289. (In Russian).

10. Moroshkin V. A, Burov V. P. Biznes-planirovanie [Business planning]. Moscow, Forum Publ., 2011. 287 p.

\section{Информация об авторах}

Грибанова Нина Николаевна - канд. экон. наук, доцент, кафедра экономики предприятия и предпринимательской деятельности, Байкальский государственный университет, 664003, г. Иркутск, ул. Ленина, 11, e-mail: miss.gribanova@bk.ru.

Шуплецов Александр Федорович - доктор экономических наук, профессор, заведующий кафедрой экономики предприятия и предпринимательской деятельности, Байкальский государственный университет экономики и права, 664003, г. Иркутск, ул. Ленина, 11, e-mail: ssa@isea.ru.

\section{Authors}

Nina N. Gribanova - PhD in Economics, Associate Professor, Chair of Enterprise Economy and Entrepreneurship, Baikal State University, 11 Lenin St., 664003, Irkutsk; e-mail: miss. gribanova@bk.ru.

Aleksandr F. Shupletsov - Doctor habil. in Economics, Professor, Head of Chair of Enterprise Economy and Entrepreneurship, Baikal National University, 11 Lenin St., 664003, Irkutsk; e-mail: ssa@isea.ru.

\section{Baikal Research Journal}




\section{Для цитирования}

Грибанова Н. Н. Особенности планирования и прогнозирования компаний на основе информационных моделей / А. Ф. Шуплецов, Н. Н. Грибанова // Baikal Research Journal. 2017. — T. 8, № 3. - DOI : 10.17150/2411-6262.2017.8(3).8.

\section{For citation}

Gribanova N. N., Shupletsov A. F. Features of corporate planning and forecasting on the basis of information models. Baikal Research Journal, 2017, vol. 8, no 3. DOI : 10.17150/24116262.2017.8(3).8. (In Russian).

\section{Baikal Research Journal}

